\title{
Potentiality of a triple microRNA classifier: miR-193a-3p, miR-23a and miR-338-5p for early detection of colorectal cancer
}

Fung Lin Yong ${ }^{1 *}$, Chee Wei Law ${ }^{1}$ and Chee Woon Wang ${ }^{2}$

\begin{abstract}
Background: MicroRNAs (miRNAs) are short, non-coding RNA molecules that act as regulators of gene expression. Circulating blood miRNAs offer great potential as cancer biomarkers. The objective of this study was to correlate the differential expression of miRNAs in tissue and blood in the identification of biomarkers for early detection of colorectal cancer (CRC).
\end{abstract}

Methods: The study was divided into two phases: (I) Marker discovery by miRNA microarray using paired cancer tissues $(n=30)$ and blood samples (CRC, $n=42$; control, $n=18)$. (II) Marker validation by stem-loop reverse transcription real time PCR using an independent set of paired cancer tissues $(n=30)$ and blood samples (CRC, $n=70$; control, $n=32$ ). Correlation analysis was determined by Pearson's test. Logistic regression and receiver operating characteristics curve analyses were applied to obtain diagnostic utility of the miRNAs.

Results: Seven miRNAs (miR-150, miR-193a-3p, miR-23a, miR-23b, miR-338-5p, miR-342-3p and miR-483-3p) have been found to be differentially expressed in both tissue and blood samples. Significant positive correlations were observed in the tissue and blood levels of miR-193a-3p, miR-23a and miR-338-5p. Moreover, increased expressions of these miRNAs were detected in the more advanced stages. MiR-193a-3p, miR-23a and miR-338-5p were demonstrated as a classifier for CRC detection, yielding a receiver operating characteristic curve area of 0.887 ( $80.0 \%$ sensitivity, $84.4 \%$ specificity and $83.3 \%$ accuracy).

Conclusion: Dysregulations in circulating blood miRNAs are reflective of those in colorectal tissues. The triple miRNA classifier of miR-193a-3p, miR-23a and miR-338-5p appears to be a potential blood biomarker for early detection of CRC.

Keywords: Colorectal cancer, MicroRNA, MiR-193a-3p, MiR-23a, MiR-338-5p

\section{Background}

Colorectal cancer (CRC) is the third most common cancer worldwide, with an estimation of 1.2 million new cases per year and more than 600,000 deaths [1-3]. The risk of CRC increases with age, whereby most cases are diagnosed in individuals aged 50 and above [4]. Incidence rate of $\mathrm{CRC}$ has been increasing in Asian countries. In Malaysia, it ranks the second after lung cancer and breast cancer in men and women, respectively [5]. The 5-year

\footnotetext{
* Correspondence: flyong88@yahoo.com

${ }^{1}$ Department of Surgery, Faculty of Medicine, University of Malaya, 50603

Kuala Lumpur, Malaysia

Full list of author information is available at the end of the article
}

survival rate exceeds $90 \%$ when CRC is detected at an early, localized stage [6]. However, most cases are diagnosed at late stages due to inconvenient settings of current CRC screening tests and low population compliance. Colonoscopy has significant contribution in the detection of neoplastic lesions, but the requirements of bowel preparation, sedation and invasive nature have hindered its widespread application as a screening tool [7]. Other structural tests such as computed tomographic colonography and double contrast barium enema are limited by the concern of radiation exposure and cost [8]. Fecal-based analyses such as occult blood, immunochemical and stool DNA tests are common noninvasive 
screening tests [9]. Nevertheless, they are confined by low sensitivity and specificity against detection of premalignant lesions [10,11]. Although stool DNA test utilizes molecular markers such as KRAS, APC and TP53 genes as detection targets, it is not favorably recommended by the US Preventive Service Task Force due to high cost, uncertainty of test performance and labor-intensive handling [12-14]. Thus, there is an imperative need for other noninvasive biomarkers to complement and improve current diagnostic and prognostic tools in CRC.

MicroRNAs (miRNAs) are short (19-22 nucleotides), non-coding RNA molecules that act as regulators of gene expression [15]. Although their main mechanism of action is through mRNA degradation or translational inhibition, they can also induce gene activation $[16,17]$. The pioneer discovery of miRNAs was initiated by Lee and colleagues in 1993 when they found lin-4, a small RNA molecule that was capable of controlling the larval development of Caenorhabditis elegans [18]. Since then, a vast number of miRNAs have been reported. To date, there are more than 2000 entries of human miRNAs in the miRNA database, miRBase 19.0, constituting around $1 \%$ of total genes that can regulate up to one third of human genome [19]. MiRNAs are evolutionary conserved across species and expressed in a tissue-specific manner [20]. They have been determined to play important roles in cancer pathophysiology such as cell proliferation, differentiation, apoptosis and metastasis [21-23]. MiRNA genes are frequently located at fragile sites and genomic regions of deletion and amplification implicated in cancers $[24,25]$. They can confer both oncogenic and tumor suppressive roles, depending upon their downstream targets [26-28]. MiRNAs are detectable in tissues, blood, feces and other body fluids such as saliva, tears and urine [29-32]. The presence of miRNAs in the circulation system is mediated via exosome transfer to the surrounding microenvironment [33,34]. Blood-based miRNA profiling has become a favorable area of research for the identification of noninvasive biomarkers in cancers and other diseases [35-38]. In addition, a study by Heneghan et al. reported a strong preference of using whole blood to serum or plasma for systemic miRNAs detection and quantification [39]. Circulating blood miRNAs are generally Ago-bound and protected from endogenous RNases that enable them to serve as stable blood biomarkers $[40,41]$.

An important concern for utilization of miRNAs as biomarkers is whether the dysregulated miRNAs are related to CRC alone or as a general mechanism in histologic progression to cancer $[29,42]$. The objective of this study was to correlate the differential expression of miRNAs in tissue and blood in the identification of biomarkers for early detection of CRC.

\section{Methods}

\section{Study design and sample selection}

A case-control study was designed to identify blood miRNAs that are reflective of those in colorectal tissues. This study was performed with the approval from Medical Ethics Committee of University of Malaya Medical Centre (UMMC) (reference number 805.9). A total of 162 participants were enrolled from January 2011 to January 2013 at UMMC. A number of 112 blood samples and a subset of 60 paired cancer tissues with adjacent normal mucosa were collected from primary CRC patients. The histology was confirmed by pathological analysis and staged according to the tumor-node-metastasis (TNM) staging system of the International Union Against Cancer. For the control group, 50 blood samples were collected from individuals who were proven to be colonic disease-free after colonoscopy. They were matched to the CRC patients according to age, gender and race. Written informed consent has been obtained from each participant. The tissue and whole blood samples were collected in tubes containing RNAlater (Ambion, Austin, TX).

\section{Total RNA isolation}

Total RNA (including miRNAs) from tissue and blood samples were extracted using Qiagen miRNeasy Mini Kit (Qiagen, Valencia, CA) and Ribopure Blood RNA Isolation Kit (Ambion) respectively, according to manufacturer's instructions. RNA concentration and integrity were determined using NanoDrop 2000 Spectrophotometer (Thermo Scientific Wilmington, DE) and Agilent 2100 Bioanalyzer (Agilent Technologies, Santa Clara, CA). RNA samples with the RNA integrity number $\geq 7.0$ and the absence of DNA contamination were used for downstream experiments [43].

\section{MiRNA microarray expression profiling and analysis}

The miRNA expression profiles were generated by GeneChip miRNA 2.0 Array (Affymetrix, Santa Clara, CA). This array contains 15,644 probe sets, covering 131 organisms and detecting 1,105 human mature miRNAs. The content is derived from Sanger miRBase miRNA database version 15.0. Briefly, $1 \mu \mathrm{g}$ of total RNA was biotin-labeled using 3DNA Array Detection Flashtag Biotin HSR RNA Labeling Kit (Genisphere LLC, Hatfield, PA). The samples were hybridized overnight in Affymetrix Hybridization Oven 640, washed and stained using Affymetrix Fluidics Station 450 and scanned with GeneChip Scanner 3000 7G. Cell intensity file was generated in the GeneChip Command Console software and used for further analysis with GeneSpring GX 12.0 (Agilent Technologies). Robust multichip averaging (RMA) algorithm was applied for background correction and probe summarization of perfect match values in each microarray chip. Median intensity values for each miRNA from the 
same replicates were calculated and subjected to quantile normalization to normalize the data across different arrays [44]. The normalized data were analyzed using $t$-test/ ANOVA analysis with $p$ value computations done asymptotically at $p<0.05$. Subsequently, the gene lists were filtered at a fold change cut-off of 1.5. Hierarchical clustering was computed using similarity measure of Euclidean distance and average linkage rule and expressed in the form of heat map and three dimensional (3D) principal component analysis (PCA) plot. The miRNA microarray data reported are MIAME compliant and have been submitted to the NCBI Gene Expression Omnibus (GEO) database (Accession: GSE39845).

Two independent miRNA microarray profiling studies of tissue and blood were conducted. In tissue miRNA array, 30 paired cancer tissue and the adjacent normal mucosa samples were pooled according to stages II $(n=10)$, III $(\mathrm{n}=10)$ and IV $(\mathrm{n}=10)$, respectively. In blood miRNA array, blood samples from $42 \mathrm{CRC}$ cases were grouped by tumor location (colon; rectum) and pooled into stages I $(\mathrm{n}=3 ; \mathrm{n}=3)$, II $(\mathrm{n}=9 ; \mathrm{n}=3)$, III $(\mathrm{n}=9 ; \mathrm{n}=3)$ and IV $(\mathrm{n}=9$; $\mathrm{n}=3$ ). Blood samples from 18 healthy controls were used for the profiling study. Due to limited availability of stage I CRC cases, only one replicate was performed for both colon and rectal samples. Similarly, the profiling analyses of rectal samples for stages II, III and IV were also performed in one replicate. On the other hand, the profiling analyses of stages II, III and IV of colon samples were performed in triplicates and control samples in six replicates, with $\mathrm{n}=3$ each. The blood samples were obtained from the same group of patients who have donated their tissue samples. The tissue and blood miRNA profiles were then correlated and used to determine the miRNAs that were concurrently expressed.

\section{Stem-loop reverse transcription real time PCR (RT-PCR) assay}

The miRNA microarray results were validated with stem-loop RT-PCR using Taqman MicroRNA Assay on StepOnePlus Real Time PCR system (Applied Biosystems, Foster City, CA). An independent set of 30 paired cancer tissues (stage II, $\mathrm{n}=10$; stage III, $\mathrm{n}=10$; stage IV, $\mathrm{n}=10$ ), 70 blood samples from CRC patients (stage I, $\mathrm{n}=19$; stage II, $\mathrm{n}=20$; stage III, $\mathrm{n}=1$; ; stage IV, $\mathrm{n}=12$ ) and 32 blood samples from healthy controls were used in the validation study. This is a two-step protocol which utilizes reverse transcription with miRNA-specific primer followed by quantitative real time PCR with Taqman probe. Seven miRNAs were selected for this purpose and the primer sequences are listed in Additional file 1 . Briefly, total RNA of 10 ng was subjected to reverse transcription using Taqman MicroRNA RT Kit which comprised of $100 \mathrm{mM}$ dNTPs, $50 \mathrm{U} / \mathrm{ul}$ Multiscribe Reverse Transcriptase, 10X RT Buffer and 20 U/ul RNase
Inhibitor (Applied Biosystems). The RT product was then diluted at 1:15 dilution and added to the reaction mixture of Taqman 2X Fast Advanced Master Mix and Taqman 20X MicroRNA Assay for RT-PCR. All assays were performed in triplicate and adhered to the protocols provided by the manufacturer. The expression of each miRNA relative to RNU48 as endogenous control was presented as $\triangle \mathrm{CT}$. A Ct value of 35 was set as the cutoff value for defining as non-detected [45,46]. Fold change was determined using comparative CT $\left(2^{-\Delta \Delta C T}\right)$ method [47].

\section{Statistical analysis}

The patients' demographics were reported as mean \pm standard deviation or frequencies and percentages for continuous and categorical variables, respectively. Microarray data analysis was carried out as outlined above. T-tests were used to determine the level of significance $(p<0.05)$ of the selected miRNAs. Correlation analysis was determined by Pearson's test. Logistic regression and receiver operating characteristics (ROC) curve analyses were applied to obtain diagnostic utility of the miRNAs. Statistical analysis was performed using IBM SPSS version 16.0 software (IBM Corporation, Armonk, NY).

\section{Results}

\section{Demographics study}

A total of 112 CRC patients and 50 healthy controls were enrolled in this study (Table 1). No significant differences were observed between the CRC patients and controls in the distribution of age $(p=0.071$, chi-square test) and gender ( $p=0.174$, Fisher's exact test). Malaysia is comprised of a multi-ethnic population. The National Cancer Registry of Malaysia has reported a higher proportion of CRC cases in the Malaysian Chinese population [5]. Thus, approximately $52 \%$ of the samples obtained were from the Malaysian Chinese and the remainders were from the Malays and Malaysian Indians ( $p=0.202$, Fisher's exact test). All CRC cases in this study were adenocarcinomas. The characteristics of the subset of 60 paired cancer tissues with adjacent normal mucosa were listed in Table 2.

\section{Tissue and blood miRNA microarray profiling}

In the discovery of global miRNA expression in cancer tissue and whole blood, two independent miRNA profiles were generated. Hierarchical clustering analyses of the tissue and blood arrays were shown in Figures 1A and $1 \mathrm{~B}$, respectively. The heat maps indicated the number of miRNAs that were differentially regulated between the normal/control group versus the cancer group. Moreover, differential expressions of the miRNAs were observed among samples of different TNM staging. 
Table 1 Patients' demographics: characteristics of CRC patient and control blood cohorts

\begin{tabular}{|c|c|c|c|c|}
\hline \multicolumn{2}{|l|}{ Characteristics } & \multirow{2}{*}{$\begin{array}{l}\text { CRC patient } \\
\text { blood cohort } \\
(n=112) \\
n(\%)\end{array}$} & \multirow{2}{*}{$\begin{array}{l}\text { Control } \\
\text { blood cohort } \\
(n=50), \\
n(\%)\end{array}$} & \multirow[t]{2}{*}{$p$ value $^{\mathrm{a}}$} \\
\hline & & & & \\
\hline \multicolumn{2}{|l|}{ Average age (years) } & $64.4 \pm 9.0$ & $61.5 \pm 9.3$ & 0.071 \\
\hline \multirow[t]{2}{*}{ Gender } & Male & 67 (59.8\%) & $24(48.0 \%)$ & 0.174 \\
\hline & Female & $45(40.2 \%)$ & $26(52.0 \%)$ & \\
\hline \multirow[t]{3}{*}{ Race } & Malay & $26(23.2 \%)$ & $15(30.0 \%)$ & 0.202 \\
\hline & Chinese & $64(57.1 \%)$ & $21(42.0 \%)$ & \\
\hline & Indian & $22(19.6 \%)$ & $14(28.0 \%)$ & \\
\hline \multirow[t]{4}{*}{ TNM stage } & 1 & $25(22.3 \%)$ & & \\
\hline & $\|$ & $32(28.6 \%)$ & & \\
\hline & III & $31(27.7 \%)$ & & \\
\hline & IV & $24(21.4 \%)$ & & \\
\hline \multirow[t]{2}{*}{ Tumor location } & Colon & $72(64.3 \%)$ & & \\
\hline & Rectum & $40(35.7 \%)$ & & \\
\hline Tumor grading & G1 & $25(22.3 \%)$ & & \\
\hline \multirow[t]{2}{*}{ (adenocarcinoma) } & $\mathrm{G} 2$ & $76(67.9 \%)$ & & \\
\hline & G3 & 11 (9.8\%) & & \\
\hline
\end{tabular}

${ }^{a} p$ value for age was calculated by chi-square test; $p$ values for gender and race were calculated by Fisher's exact test.

Many miRNAs that were poorly expressed in normal/ control samples have been determined to be highly expressed in CRC samples. At the fold change cut-off of 1.5 , the tissue miRNA array revealed 40 significantly upregulated miRNAs and 32 down-regulated miRNAs (Additional file 2A). On the other hand, the blood

Table 2 Patients' demographics: characteristics of the subset of paired cancer tissue from CRC patients

\begin{tabular}{lll}
\hline Characteristics & & $\begin{array}{l}\text { Subset of paired cancer tissue } \\
\text { (n=60), } \mathbf{n}(\%)\end{array}$ \\
\hline Average age (years) & & $63.8 \pm 10.6$ \\
Gender & Male & $33(55.0 \%)$ \\
& Female & $27(45.0 \%)$ \\
Race & Malay & $10(16.7 \%)$ \\
& Chinese & $38(63.3 \%)$ \\
& Indian & $12(20.0 \%)$ \\
TNM stage & I & 0 \\
& II & $20(33.3 \%)$ \\
& III & $20(33.3 \%)$ \\
Tumor location & IV & $20(33.3 \%)$ \\
& Colon & $60(100.0 \%)$ \\
Tumor grading & Rectum & 0 \\
(adenocarcinoma) & G1 & $13(21.7 \%)$ \\
& G2 & $43(71.7 \%)$ \\
\hline
\end{tabular}

miRNA array only revealed 15 significantly up-regulated and 9 down-regulated miRNAs (Additional file 2B). Next, 3D PCA plots were computed to provide visual representations of the samples. The 3D PCA plot distributes the samples into a three dimensional space based on variance in miRNA gene expressions. Samples from the same group and stage were found to be clustered together in distinctive patterns, as shown in the Figure $1 \mathrm{C}$ and $1 \mathrm{D}$, respectively.

The tissue array revealed a higher number of deregulated miRNAs and those that were concurrently expressed in blood array were selected for further validation (Figure 2). The selected miRNAs consisted of two down-regulated (miR-150 and miR-342-3p) and five upregulated miRNAs (miR-193a-3p, miR-23a, miR-23b, miR-338-5p and miR-483-3p).

\section{Validation of miRNA expressions by RT-PCR}

The selected miRNAs from miRNA profiling were validated with RT-PCR using an independent set of tissue and blood samples. RNU48 was chosen as the endogenous control in data normalization and its expression was found to be stable and reproducible. No significant difference was found in the level of RNU48 $(p=0.483)$ between CRCs and controls. Using a new subset of 30 paired cancer tissue and adjacent normal mucosa samples, significant deregulations were noticed in the panel of seven miRNAs using paired $t$-test $(p=0.039$ for miR150, $p=0.037$ for miR-193a-3p, $p=0.031$ for miR-23a, $p=0.025$ for miR-23b, $p=0.023$ for miR-338-5p, $p=0.025$ for miR-342-3p, $p=0.009$ for miR-483-3p). For blood samples validation, significant elevations were detected in the levels of miR-193a-3p $(p<0.001)$, miR-23a $(p=0.043)$, miR-23b $(p=0.045)$, miR-338-5p $(p<0.001)$ and miR-483$3 \mathrm{p}(p=0.010)$ in CRC cases. However, no significant difference was observed in the levels of miR-150 $(p=0.450)$ and miR-342-3p $(p=0.560)$. The absolute $\mathrm{Ct}$ values of miRNAs in both tissue and blood samples ranged from 21 to 28 for miR-150, 27 to 33 for miR-193a-3p, 23 to 30 for miR-23a, 23 to 31 for miR-23b, 28 to 33 for miR-338-5p, 25 to 29 for miR-342-3p and 26 to 33 for miR-483-3p.

\section{Relationship between tissue and blood miRNAs}

Given that miR-193a-3p, miR-23a, miR-23b, miR-338-5p and miR-483-3p were significantly up-regulated in both tissue and blood samples from the validation study, we have proceeded to investigate the correlation between them. The purpose is to provide a stronger confirmation that deregulated miRNA expressions in the systemic circulation are potential indicators of what is happening at tissue level. Controlling for age, gender, race and TNM staging, correlation analyses between tissue and blood RTPCR data for miR-193a-3p $(\mathrm{r}=0.811, p<0.001)$, miR-23a $(\mathrm{r}=0.827, \quad p<0.001), \quad$ miR-23b $\quad(\mathrm{r}=0.044, \quad p=0.818)$, 

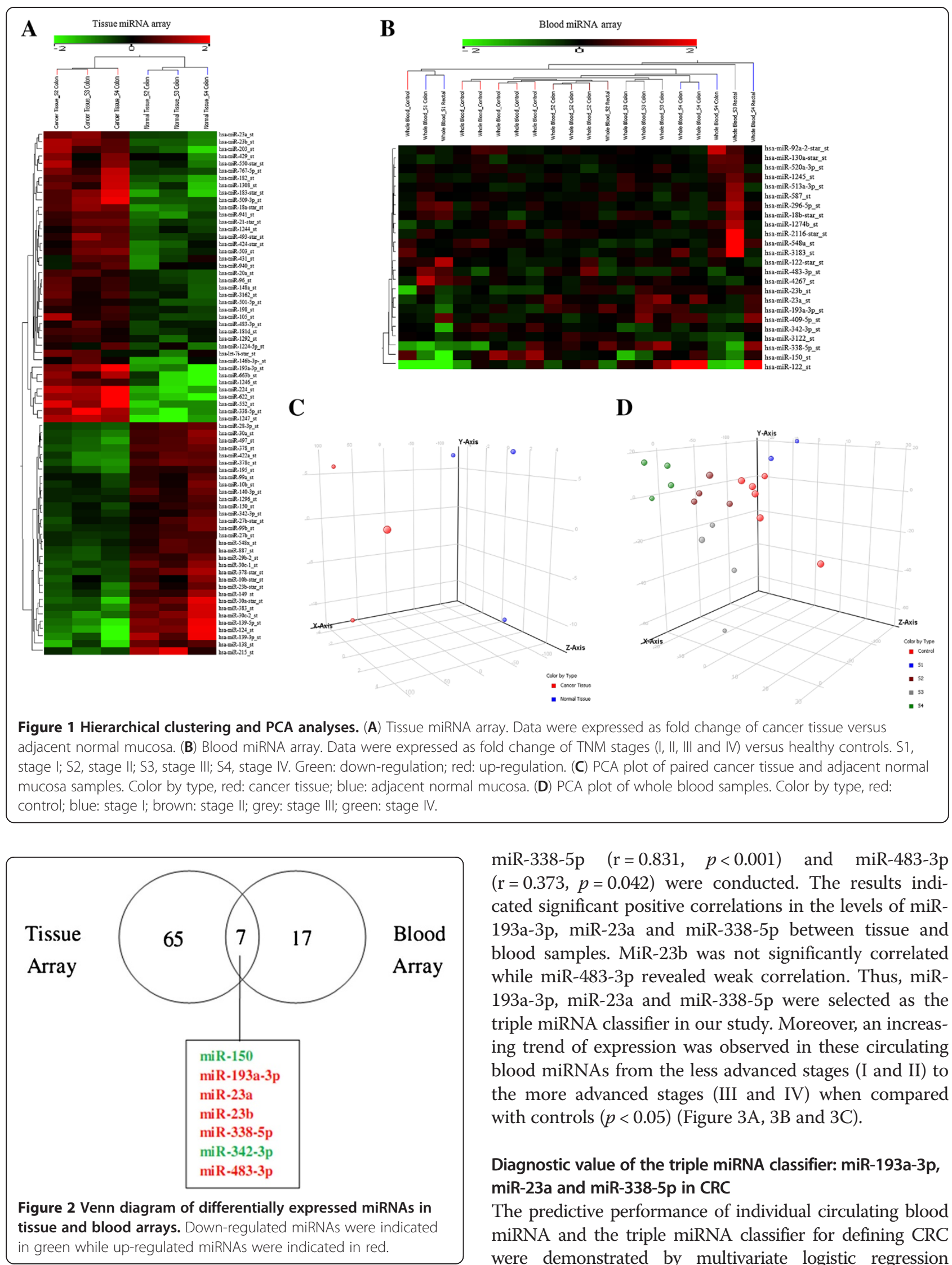

miR-338-5p $\quad(\mathrm{r}=0.831, \quad p<0.001) \quad$ and $\operatorname{miR}-483-3 \mathrm{p}$ $(\mathrm{r}=0.373, p=0.042)$ were conducted. The results indicated significant positive correlations in the levels of miR193a-3p, miR-23a and miR-338-5p between tissue and blood samples. MiR-23b was not significantly correlated while miR-483-3p revealed weak correlation. Thus, miR193a-3p, miR-23a and miR-338-5p were selected as the triple miRNA classifier in our study. Moreover, an increasing trend of expression was observed in these circulating blood miRNAs from the less advanced stages (I and II) to the more advanced stages (III and IV) when compared with controls $(p<0.05)$ (Figure 3A, 3B and 3C).

Diagnostic value of the triple miRNA classifier: miR-193a-3p, miR-23a and miR-338-5p in CRC

The predictive performance of individual circulating blood miRNA and the triple miRNA classifier for defining CRC were demonstrated by multivariate logistic regression 

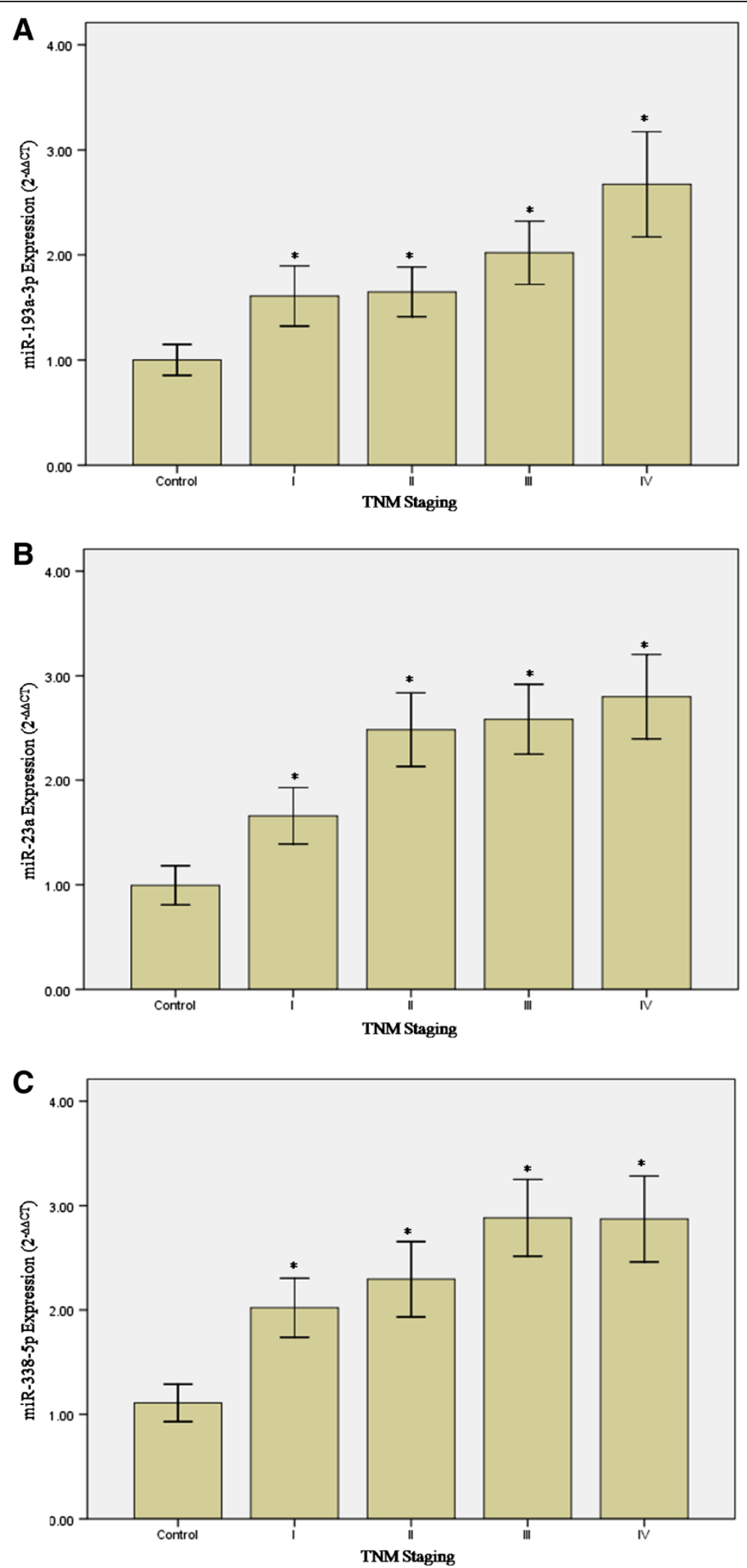

Figure 3 Expression levels of circulating blood (A) miR-193a-3p, (B) miR-23a and (C) miR-338-5p. An increasing trend of expression was observed in the circulating blood miRNAs in the more advanced stages when compared with controls. Statistically significant differences were tested at ${ }^{*} p<0.05$. MiRNA expression was presented as fold change $\left(2^{-\triangle \triangle C T}\right)$; error bars represent mean \pm SEM. 
Table 3 Multivariate logistic regression analysis of individual blood miRNA and miRNA classifier of miR-193a-3p, miR-23a and miR-338-5p

\begin{tabular}{|c|c|c|c|c|c|c|c|}
\hline Statistical parameters & miR-193a-3p & miR-23a & miR-338-5p & $\begin{array}{l}\operatorname{miR}-193 a-3 p+ \\
\text { miR-23a }\end{array}$ & $\begin{array}{l}\operatorname{miR}-193 a-3 p+ \\
\operatorname{miR}-338-5 p\end{array}$ & $\begin{array}{l}\operatorname{miR}-23 a+ \\
\operatorname{miR}-338-5 p\end{array}$ & $\begin{array}{l}\text { miR-193a-3p + miR-23a + } \\
\text { miR-338-5p }\end{array}$ \\
\hline$A \cup C$ & 0.852 & 0.787 & 0.871 & 0.852 & 0.872 & 0.873 & 0.887 \\
\hline $95 \% \mathrm{Cl}$ & $0.768-0.935$ & $0.685-0.889$ & $0.800-0.942$ & $0.770-0.935$ & $0.798-0.946$ & $0.803-0.942$ & $0.821-0.953$ \\
\hline Sensitivity (\%) & 100.0 & 94.3 & 81.4 & 74.3 & 94.3 & 81.4 & 80.0 \\
\hline Specificity (\%) & 56.2 & 53.1 & 75.0 & 81.2 & 65.6 & 75.0 & 84.4 \\
\hline Accuracy (\%) & 83.3 & 81.4 & 83.3 & 83.3 & 83.3 & 82.4 & 83.3 \\
\hline Youden's Index ${ }^{a}$ & 0.562 & 0.474 & 0.564 & 0.555 & 0.599 & 0.564 & 0.644 \\
\hline Cut-off value & 0.346 & 0.502 & 0.640 & 0.745 & 0.474 & 0.636 & 0.728 \\
\hline
\end{tabular}

${ }^{\text {a }}$ Youden's Index = sensitivity + specificity -1 .

analysis (Table 3). The triple miRNA classifier of miR-193a -3p, miR-23a and miR-338-5p gave the best performance and could be a potential biomarker in the detection of CRC. The optimal cut-off value for sensitivity and specificity was determined based on the highest Youden's Index in ROC curve analysis [48]. The triple classifier has a stronger differentiation power than individual or double combination of miRNAs. The classifier has an increased area under ROC curve (AUC) of 0.887 (confidence interval [CI]: $0.821-0.953)$ with $80.0 \%$ sensitivity, $84.4 \%$ specificity and $83.3 \%$ accuracy, illustrating an improved diagnostic value of these triple combination of miRNAs (Figure 4).

\section{Discussion}

MiRNA profiling studies in CRC and other diseases have been vastly reported [35-38]. For instance, a recent tissue miRNA profiling study by Piepoli et al. revealed a cluster of dysregulated miRNAs (miR-195, miR-1280, miR-140-3p and miR-1246) that could be used to distinguish between colorectal and pancreatic cancers [49]. An investigation by
Hamfjord et al. using high throughput sequencing in paired cancer tissues has reported 16 novel miRNAs (miR-4903p, miR-628-3p/-5p, miR-1297, miR-3151, miR-3163, miR-3622a-5p, miR-3656, miR-105, miR-549, miR-1269, miR-1827, miR-3144-3p, miR-3177, miR-3180-3p and miR-4326) that have not been previously described in CRC [50]. For blood-based miRNA profiling, Ahmed et al. have identified a huge panel of differentially expressed miRNAs in sporadic colon cancer patients [51]. Our data corresponded to theirs whereby an overlap of certain markers (miR-130a, miR-150, miR-18b, miR-338, miR-342 and miR92a) was observed in our blood array study. Apart from that, $\mathrm{Ng}$ et al. have evaluated a panel of 95 miRNAs using real-time PCR-based array and plasma miR-17-3p and miR-92 were shown to be significantly expressed between the CRC cases and controls [52]. The main aspect of our study is to determine whether the circulating blood miRNAs are reflective of those in the tissues. Therefore, we have investigated the correlation of miRNA expressions between paired cancer tissue and

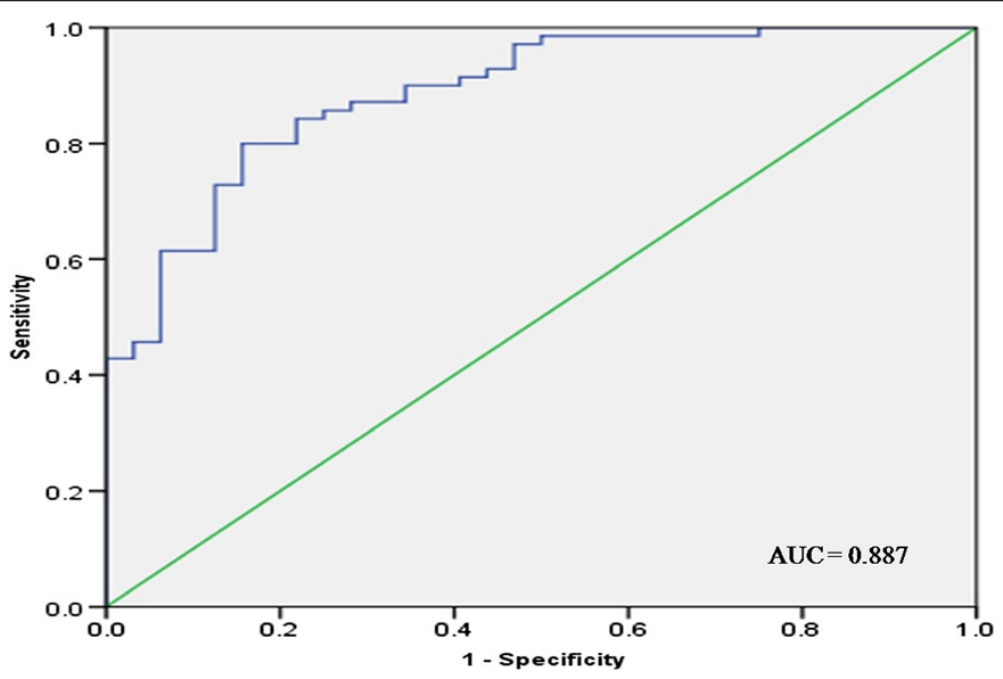

Figure 4 ROC curve analysis using the triple miRNA classifier of miR-193a-3p, miR-23a and miR-338-5p. The triple miRNA classifier yielded an AUC of 0.887 ( $95 \% \mathrm{Cl}: 0.821-0.953$ ) with $80.0 \%$ sensitivity, $84.4 \%$ specificity and $83.3 \%$ accuracy. 
whole blood of CRC patients. The levels of miR-193a-3p, miR-23a and miR-338-5p were significantly up-regulated and positively correlated in both the tissue and blood samples. The triple miRNA classifier identified in this study was of high sensitivity (80.0\%), specificity (84.4\%) and accuracy $(83.3 \%)$ in defining CRC. The findings have collectively implicated the potentiality of circulating blood miRNAs as noninvasive biomarkers.

Mir-193a-3p is part of the miR-193 family, together with miR-193a-5p and miR-193b. Nevertheless, the information on miR-193a-3p is limited and its molecular mechanism and role in carcinogenesis remain largely unknown. To our knowledge, the present paper is the first report on the upregulation of miR-193a-3p in CRC. Although miR-193a-3p has not been mentioned in CRC, its dysregulation has been observed in pleural mesothelioma, ostersarcoma and oral cancer, suggesting its impact in tumorigenesis [53-55]. Clearly, the role of miR-193a-3p in cancer needs to be robustly investigated.

The role of miR-23a has been reported with varying conclusions. Recently, Jahid et al. revealed the function of miR23a in promoting the migration and invasion of CRC cells and stem cells by down-regulating metastasis suppressor 1 (MTSS1) gene [56]. The finding is consistent with our study whereby there is an increasing expression of miR-23a in the more advanced tumors. A deep sequencing project using serum samples has demonstrated a common up-regulation of miR-23a in CRC and lung cancer patients [57]. An in vitro study by Zhu et al. using gastric adenocarcinoma cell line (MGC803) revealed a growth-promoting function of miR-23a via regulation of interleukin-6 receptor (IL-6R) gene [58]. Besides its individualistic function, miR-23a has been shown to possess cooperative functions with miR-27a and miR-24 [59]. The three miRNAs are derived from a single primary transcript, located on chromosome 9q22. These miRNAs have been bioinformatically predicted to regulate cell proliferation and tissue development via Wnt signaling pathway [60]. Wnt pathway is associated with advancement of dysplasia in aberrant crypt foci and acts as 'gatekeeper' in the initiation of adenoma-carcinoma sequences in CRC. In addition, Rogler et al. found miR-23b, a paralog of miR-23a to have an amplification effect with miR-23a in regulating transforming growth factor beta signaling by targeting $S M A D$ genes [61]. This is in support with our microarray and validation studies whereby mir-23a and miR-23b were discovered to be significantly up-regulated in both tissue and blood samples. MiR-23a, together with miR-23b have been reported to play certain roles in glutamine catabolism, cell cycle regulation and glucose metabolism via regulation of $c-M y c$ gene $[59,62]$. On the contrary, miR-23a expression has also been found to be repressed in several malignancies, including oral squamous cell carcinoma and acute promyelocytic leukemia $[55,63]$. The findings unveiled the possibility of diverse miRNA functions in different cell types and diseases.

MiR-338-3p and miR-338-5p are isoforms of miR-338. In general, over-expression of miR-338 has been observed in many cancers, namely CRC, hepatocellular carcinoma and head and neck/oral cancer [64-66]. A tissue miRNA profiling by Schetter et al. revealed 37 miRNAs, including miR-338, to be differentially expressed in CRC tissues when compared with paired noncancerous tissues [64]. In a recent investigation on CRC recurrence-related miRNAs by Ju et al., miR-338-5p was found to be significantly upregulated and positively correlated with cancer metastasis [67]. Our findings corresponded to their study whereby mir-338-5p expression was shown to be significantly higher in the more advanced tumors.

An individual miRNA is definitely not an appealing marker in discriminating CRC. The fact that miRNAs could act as cell proliferating factors in certain cancers and apoptotic factors in another has evoked the necessity of studying their cooperative functions in order to provide a holistic picture of miRNA regulations in cancer biology and pathogenesis.

\section{Conclusion}

Dysregulations in circulating blood miRNAs are reflective of those in colorectal tissues. The triple miRNA classifier of miR-193a-3p, miR-23a and miR-338-5p appears to be a potential blood biomarker for early detection of CRC. Our study serves as an exploratory basis for further investigation in larger prospective and randomized clinical studies with higher number of samples from healthy controls and patients of advanced adenoma and various stages of CRC. A noninvasive miRNA screening assay using the triple miRNA classifier could then be developed to identify asymptomatic individuals with colorectal neoplasia prior to more invasive colonoscopy examination.

\section{Additional files}

Additional file 1: Taqman 20X MicroRNA Assays. Reporter dye: FAM;
reporter quencher: NFQ (Applied Biosystems).
Additional file 2: (A) List of significantly deregulated miRNAs
( $\boldsymbol{p}<\mathbf{0 . 0 5}$ ) from tissue miRNA array. MiRNA expression was shown as fold
change of cancer tissue versus adjacent normal mucosa. Positive value
denotes up-regulation and negative value denotes down-regulation.
(B) List of significantly deregulated miRNAs ( $\boldsymbol{p}<0.05)$ from blood miRNA
array. MiRNA expression was shown as fold change of TNM stages (I, II, III
and IV) versus control samples. Positive value denotes up-regulation and
negative value denotes down-regulation.

\section{Abbreviations}

3D: Three dimensional; AUC: Area under ROC curve; Cl: Confidence interval; CRC: Colorectal cancer; GEO: Gene Expression Omnibus; IL-6R: Interleukin-6 receptor; miRNAs: microRNAs; MTSS1: Metastasis suppressor 1; PCA: Principal component analysis; RMA: Robust multichip averaging; ROC: Receiver operating characteristics; RT-PCR: Reverse transcription real time PCR; TNM: Tumor-node-metastasis; UMMC: University of Malaya Medical Centre. 


\section{Competing interests}

The authors declare that they have no competing interests.

\section{Authors' contributions}

FLY has carried out the experiments and drafting of the manuscript. CWL was responsible for collection of samples and clinical interpretations. CWW was responsible for overall supervision. All authors contributed equally in study design, data analysis and have approved the final manuscript.

\section{Acknowledgements}

The authors would like to thank Associate Professor Dr April Camilla Roslani, Dr Sandip Kumar, Dr Nurhashim Haron, Dr Chieng Tiong How and Dr Chong Hoong Yin for the help in tissue and blood specimens' collection. The authors also wish to acknowledge Malaysia Genome Institute (Microarray) for providing the Bioanalyzer service and GeneSpring GX 12.0 software. This research was funded by the University of Malaya (Malaysia) Research Grant (RG313-11HTM) and University of Malaya (Malaysia) Postgraduate Research Grant (PV020-2011A) for CWL and FLY, respectively.

\section{Author details}

${ }^{1}$ Department of Surgery, Faculty of Medicine, University of Malaya, 50603 Kuala Lumpur, Malaysia. ²Department of Biochemistry, Faculty of Medicine, MAHSA University, 59100 Kuala Lumpur, Malaysia.

Received: 6 October 2012 Accepted: 14 May 2013

Published: 8 June 2013

\section{References}

1. Worldwide cancer statistics. http://info.cancerresearchuk.org/cancerstats/ world/cancer-worldwide-the-global-picture.

2. Jemal A, Bray F, Center MM, Ferlay J, Ward E, Forman D: Global cancer statistics. CA Cancer J Clin 2011, 61:69-90.

3. Bray F, Jemal A, Grey N, Ferlay J, Forman D: Global cancer transitions according to the Human Development Index (2008-2030): a populationbased study. Lancet Oncol 2012, 13(8):790-801.

4. American Cancer Society: Cancer Facts \& Figures 2012. Atlanta: American Cancer Society; 2012.

5. Zainal Ariffin O, Nor Saleha IT: National Cancer Registry Report 2007. Malaysia: Ministry of Healthy; 2011.

6. McFarland EG, Levin B, Lieberman DA, Pickhardt PJ, Johnson CD, Glick SN, Brooks D, Smith RA: Revised colorectal screening guidelines: joint effort of the American Cancer Society, U.S. Multisociety Task Force on Colorectal Cancer, and American College of Radiology. Radiology 2008, 248:717-720.

7. Tests to detect colorectal cancer and polyps. http://www.cancer.gov/ cancertopics/factsheet/detection/colorectal-screening.

8. Neri E, Faggioni L, Cerri F, Turini F, Angeli S, Cini L, Perrone F, Paolicchi F, Bartolozzi C: CT colonography versus double-contrast barium enema for screening of colorectal cancer: comparison of radiation burden. Abdom Imaging 2010, 35:596-601.

9. Choong MK, Tsafnat G: Genetic and epigenetic biomarkers of colorectal cancer. Clin Gastroenterol Hepatol 2012, 10:9-15.

10. Khalid-de Bakker CA, Jonkers DM, Sanduleanu S, de Bruïne AP, Meijer GA, Janssen JB, van Engeland M, Stockbrügger RW, Masclee AA: Test performance of immunologic fecal occult blood testing and sigmoidoscopy compared with primary colonoscopy screening for colorectal advanced adenomas. Cancer Prev Res 2011, 4(10):1563-1571.

11. Imperiale TF, Ransohoff DF, Itzkowitz SH, Turnbull BA, Ross ME: Fecal DNA versus fecal occult blood for colorectal-cancer screening in an average risk population. $N$ Engl J Med 2004, 351:2704-2714.

12. Zou H, Taylor WR, Harrington JJ, Hussain FTN, Cao X, Loprinzi CL, Levine TR, Rex DK, Ahnen D, Knigge KL, et al: High detection rates of colorectal neoplasia by stool DNA testing with a novel digital melt curve assay. Gastroenterology 2009, 136:459-470.

13. U.S. Preventive Services Task Force: Screening for colorectal cancer: U.S. Preventive Services Task Force recommendation statement. Ann Intern Med 2008, 149(9):627-637.

14. Ahlquist DA, Sargent DJ, Loprinzi CL, Levin TR, Rex DK, Ahnen DJ, Knigge K, Lance MP, Burgart L, Hamilton SR, et al: Stool DNA and occult blood testing for screen detection of colorectal neoplasia. Ann Intern Med 2008, 149(7):441-450.
15. Bartel DP: MicroRNAs: genomics, biogenesis, mechanism, and function. Cell 2004, 116:281-297.

16. Lee YS, Dutta A: MicroRNAs in cancer. Annu Rev Pathol 2009, 4:199-227.

17. Li L-C, Okino ST, Zhao H, Pookot D, Place RF, Urakami S, Enokida H, Dahiya R: Small dsRNAs induce transcriptional activation in human cells. Proc Natl Acad Sci USA 2006, 103(46):17337-17342.

18. Lee RC, Feinbaum RL, Ambros V: The C.elegans heterochronic gene lin-4 encodes small RNAs with antisense complementarity to lin-14. Cell 1993, 75:843-854.

19. Kozamara A, Griffiths-Jones S: miRBase: integrating microRNA annotation and deep-sequencing data. Nucleic Acids Res 2011, 39:D152-D157.

20. Esquela-Kerscher A, Slack FJ: Oncomirs - microRNAs with a role in cancer. Nat Rev Cancer 2006, 6:259-269.

21. Bueno MJ, Malumbres M: MicroRNA and the cell cycle. Biochim Biophys Acta 2011, 1812(5):592-601.

22. Henegan HM, Miller N, Kerin MJ: MiRNAs as biomarkers and therapeutic targets in cancer. Curr Opin Pharmacol 2010, 10:543-550.

23. Lima RT, Busacca S, Almeida GM, Gaudino G, Fennell DA, Vasconcelos MH: MicroRNA regulation of core apoptosis pathways in cancer. Eur J Cancer 2011, 47:163-174.

24. Calin GA, Sevignani C, Dumitru CD, Hyslop T, Noch E, Yendamuri S, Shimizu M, Rattan S, Bullrich F, Negrini M, et al: Human microRNA genes are frequently located at fragile sites and genomic regions involved in cancers. Proc Natl Acad Sci USA 2004, 101(9):2999-3004.

25. Koturbash I, Zemp FJ, Pogribny I, Kovalchuk O: Small molecules with big effects: the role of the microRNAome in cancer and carcinogenesis. Mutat Res 2011, 722:94-105.

26. Babashah S, Soleimani M: The oncogenic and tumour suppresive roles of microRNAs in cancer and apoptosis. Eur J Cancer 2011, 47:1127-1137.

27. Groce CM: Causes and consequences of microRNA dysregulation in cancer. Nat Rev Genet 2009, 10:704-714.

28. Liu M, Chen H: The role of microRNAs in colorectal cancer. J Genet Genomics 2010, 37:347-358.

29. Volinia S, Calin GA, Liu CG, Ambs S, Cimmino A, Petrocca F, Visone R, Lorio $M$, Roldo C, Ferracin M, et al: A microRNA expression signature of human solid tumors defines cancer gene targets. Proc Natl Acad Sci USA 2006, 103(7):2257-2261.

30. Yu DC, Li QC, Ding XW, Ding YT: Circulating microRNAs: potential biomarkers for cancer. Int J Mol Sci 2011, 12:2055-2063.

31. Weber JA, Baxter DH, Zhang S, Huang DY, Huang KH, Lee MJ, Galas DJ, Wang K: The microRNA spectrum in 12 body fluids. Clin Chem 2010, 56(11):1733-1741.

32. Link A, Balaguer F, Shen Y, Nagasaka T, Lozano JJ, Boland CR, Goel A: Fecal microRNAs as novel biomarkers for colon cancer screening. Cancer Epidemiol Biomarkers Prev 2010, 19(7):1766-1774.

33. Valadi $H$, Ekstrom $K$, Bossios A, Sjostrand M, Lee JJ, Lotvall JO: Exosome-mediated transfer of mRNAs and microRNAs is a novel mechanism of genetic exchange between cells. Nat Cell Biol 2007, 9:654-659.

34. Hunter MP, Ismail N, Zhang X, Aguda BD, Lee EJ, Yu L, Xiao T, Schafer J, Ting Lee M-L, Schmittgen TD, et al: Detection of microRNA expression in human peripheral blood microvesicles. PLoS One 2008, 3(11):e3694.

35. Di Stefano V, Zaccagnini G, Capogrossi MC, Martelli F: microRNAs as peripheral blood biomarkers of cardiovascular disease. Vascul Pharmacol 2011, 55:111-118.

36. Zhang J, Zhao H, Gao Y, Zhang W: Secretory miRNAs as novel cancer biomarkers. Biochim Biophys Acta 2012, 1826(1):32-43.

37. Zampetaki A, Kiechl S, Drozdov I, Willeit P, Mayr U, Prokopi M, Mayr A, Weger S, Oberhollenzer F, Bonora E, et al: Plasma microRNA profiling reveals loss of endothelial miR-126 and other microRNAs in type 2 diabetes. Circ Res 2010, 107:810-817.

38. Schrauder MG, Strick R, Schulz-Wendtland R, Strissel PL, Kahmann L, Loehberg CR, Lux MP, Jud SM, Hartmann A, Hein A, et al: Circulating microRNAs as potential blood-based markers for early stage breast cancer detection. PLoS One 2012, 7(1):e29770.

39. Heneghan HM, Miller N, Lowery AJ, Sweeney KJ, Newell J: Circulating microRNAs as novel minimally invasive biomarkers for breast cancer. Ann Surg 2010, 251:499-505.

40. Kosaka N, Iguchi H, Ochiya T: Circulating microRNA in body fluid: a new potential biomarker for cancer diagnosis and prognosis. Cancer Sci 2010, 101(10):2087-2092. 
41. Turchinovich A, Weiz L, Langheinz A, Burwinkel B: Characterization of extracellular miRNA. Nucleic Acids Res 2011, 39(16):7223-7233.

42. Luo X, Burwinkel B, Tao S, Brenner H: MicroRNA signatures: novel biomarker for colorectal cancer? Cancer Epidemiol Biomarkers Prev 2011, 20(7):1272-1286

43. Schroeder A, Mueller O, Stocker S, Salowsky R, Leiber M, Gassmann M, Lightfoot S, Menzel W, Granzow M, Ragg T: The RIN: an RNA integrity number for assigning integrity values to RNA measurements. BMC Mol Biol 2006, 7:3.

44. Irizarry RA, Hobbs B, Collin F, Beazer-Barclay YD, Antonellis KJ, Scherf $U$, Speed TP: Exploration, normalization, and summaries of high density oligonucleotide array probe level data. Biostatistics 2003, 4:249-264.

45. Jordan JA, Durso MB: Real-time polymerase chain reaction for detecting bacterial DNA directly from blood of neonates being evaluated for Sepsis. J Mol Diagn 2005, 7(5):575-581.

46. Caraguel CGB, Stryhn H, Gagne N, Dohoo IR, Hammell KL: Selection of a cutoff value for real-time polymerase chain reaction results to fit a diagnostic purpose: analytical and epidemiologic approaches. J Vet Diagn Invest 2011, 23:2-15.

47. Yuan JS, Reed A, Chen F, Stewart CN Jr: Statistical analysis of real-time PCR data. BMC Bioinformatics 2006, 7:85

48. Obuchowski NA: ROC analysis. AJR Am J Roentgenol 2005, 184:364-372

49. Piepoli A, Tavano F, Copetti M, Mazza T, Palumbo O, Panza A, di Mola FF, Pazienza V, Mazzoccoli G, Biscaglia G, et al: Mirna expression profiles identify drivers in colorectal and pancreatic cancers. PLOS One 2012, 7(3):e33663.

50. Hamfjord J, Stangeland AM, Hughes T, Skrede ML, Tveit KM, Ikdahl T, Kure $\mathrm{EH}$ : Differential expression of miRNAs in colorectal cancer: comparison of paired tumor tissue and adjacent normal mucosa using high-throughput sequencing. PLoS One 2012, 7(4):e34150.

51. Ahmed FE, Amed NC, Vos PW, Bonnerup C, Atkins JN, Casey M, Nuovo GJ, Naziri W, Wlley JE, Allison RR: Diagnostic microRNA markers to screen for sporadic human colon cancer in blood. Cancer Genomics Proteomics 2012, 9(4):179-192.

52. Ng EK, Chong WW, Jin H, Lam EK, Shin VY, Yu J: Differential expression of microRNAs in plasma of patients with colorectal cancer: a potential marker for colorectal cancer screening. Gut 2009, 58:1375-1381

53. Benjamin H, Lebanony D, Rosenwald S, Cohen L, Gibori H, Barabash N, Ashkenazi K, Goren E, Meiri E, Morgenstern S, et al: A diagnostic assay based on microRNA expression accurately identifies malignant pleural mesothelioma. J Mol Diagn 2010, 12(6):771-779.

54. Baumhoer D, Zillmer S, Unger $K$, Rosemann M, Atkinson MJ, Irmler M, Beckers J, Siggelkow $H$, Von Luettichau I, Jundt $G$, et al: MicroRNA profiling with correlation to gene expression revealed the oncogenic miR-17-92 cluster to be up-regulated in osteosarcoma. Cancer Genet 2012, 205:212-219.

55. Kozaki K, Imoto I, Mogi S, Omura K, Inazawa J: Exploration of tumorsuppressive microRNAs silenced by DNA hypermethylation in oral cancer. Cancer Res 2008, 68(7):2094-2105.

56. Jahid S, Sun J, Edwards RA, Dizon D, Panarelli NC, Milsom JW, Sikandar SS, Gumus ZH, Lipkin SM: miR-23a promotes the transition from indolent to invasive colorectal cancer. Cancer Discov 2012, 2(6):540-553.

57. Chen X, Ba Y, Ma L, Cai X, Yin Y, Wang K, Guo J, Zhang Y, Chen J, Guo $X$, et al: Characterization of microRNAs in serum: a novel class of biomarkers for diagnosis of cancer and other diseases. Cell Res 2008, 18:997-1006.

58. Zhu LH, Liu T, Tang H, Tian RQ, Su C, Liu M, Li X: MicroRNA-23a promotes the growth of gastric adenocarcinoma cell line MGC803 and downregulates interleukin-6 receptor. FEBS J 2010, 277:3726-3734.

59. Chhabra R, Dubey $R$, Saini N: Cooperative and individualistic functions of the microRNAs in the miR23a $\sim 27 \mathrm{a} \sim 24-2$ cluster and its implication in human diseases. Mol Cancer 2010, 9:232.

60. Willert $\mathrm{K}$, Jones KA: Wnt signaling: is the party in the nucleus? Genes Dev 2006, 20:1394-1404

61. Rogler CE, LeVoci L, Ader T, Massimi A, Tchaikovskaya T, Norel R, Rogler LE: MicroRNA-23b cluster microRNAs regulate transforming growth factor-beta/bone morphogenetic protein signaling and liver stem cell differentiation by targeting smads. Hepatology 2009, 50:575-584
62. Gao P, Tchernyshyov I, Chang TC, Lee YS, Kita K, Ochi T, Zeller K, De Marzo AM, Van Eyk JE, Mendell JT, et al: c-Myc suppression of miR-23a/b enhances mitochondrial glutaminase and glutamine metabolism. Nature 2009, 458(7239):762-765.

63. Saumet A, Vetter G, Bouttier M, Portales-Casamar E, Wasserman WW, Maurin T, Mari B, Barbry P, Vallar L, Friederich E, et al: Transcriptional repression of microRNA genes by PML-RARA increases expression of key cancer proteins in acute promyelocytic leukemia. Blood 2009, 113(2):412-421.

64. Schetter AJ, Leung SY, Sohn JJ, Zanetti KA, Bowman ED, Yanaihara N, Yuen ST, Chan TL, Kwong DLW, Au GKH, et al: MicroRNA expression profiles associated with prognosis and therapeutic outcome in colon adenocarcinoma. JAMA 2008, 299(4):425-436

65. Budhu A, Jia HL, Forgues M, Liu CG, Goldstein D, Lam A, Zanetti KA, Ye QH, Qin LX, Croce CM, et al: Identification of metastasis-related microRNAs in hepatocellular carcinoma. Hepatology 2008, 47(3):897-907.

66. Wong TS, Liu XB, Wong BYH, Ng WM, Yuen APW, Wei WI: Mature miR-184 as potential oncogenic microRNA of squamous cell carcinoma of tongue. Clin Cancer Res 2008, 14(9):2588-2592.

67. Ju JA, Huang YC, Lan SH, Wang TH, Lin PC, Lee JC, Niu KC, Tian YF, Liu HS: Identification of colorectal cancer recurrence-related microRNAs. GMBHS 2012, 4:19-20.

doi:10.1186/1471-2407-13-280

Cite this article as: Yong et al:: Potentiality of a triple microRNA classifier: miR-193a-3p, miR-23a and miR-338-5p for early detection of colorectal cancer. BMC Cancer 2013 13:280,

\section{Submit your next manuscript to BioMed Central and take full advantage of:}

- Convenient online submission

- Thorough peer review

- No space constraints or color figure charges

- Immediate publication on acceptance

- Inclusion in PubMed, CAS, Scopus and Google Scholar

- Research which is freely available for redistribution 